\title{
El ganado vacuno en Sumer y Acad
}

\author{
Cristina Delgado Linacero*
}

\section{SUMMARY}

Cattle were a very important domesticated species in the Near East with goats and sheep. They hold a special and central place in economy of agro-pastoral ancient society in Mesopotamia, providing good resources of meat, dairy products, leather and dung, besides labor and draft. However, the highest cost of cattle breeding resulted in a poor diet from these peoples and led to the almost exclusive possession of these animals by the ruling classes. The valuable and commercial characteristic of cattle was transferred to the religious sphere where its offering and sacrifice became the best gift for the divinity. The sacrificial feasts turned out to be, in many cases, an excellent occasion for the consumption of a special dish which only few people could normally enjoy everyday life.

\section{INTRODUCCIÓN}

Desde los tiempos más remotos de la historia de la Humanidad, el ganado vacuno ha desempeñado un papel fundamental en el desarrollo económico de los antiguos pobladores del Mediterráneo y del área del Próximo Oriente. Los haliazgos óseos, procedentes de los yacimientos arqueológicos, señalan esta última región como cuna del proceso conocido como domesticación. Hacia el VII milenio a.C., la domesticación ${ }^{1}$ del bovino era ya

* Laboratorio de Arqueozoología (U.A.M.). Este trabajo se ha beneficiado parcialmente como PB. 94-0186 y ha sido financiado por la DGITY.

1 ReED, C.H.: 1969. The Pattern of Animal Domestication in the Prehistoric Near East. En, UCKo, P. / DIMBLEBY, G.W. The Domestication and Explotation of Animals and Plants ; BÖKÖNYI, S.: 1976. Development of Early Stock Rearing in the Near East. Nature, vol. 264, n. ${ }^{\circ} 5.581$. 
un hecho. Aldeas como Buqras o Tell es $\operatorname{Sinn}^{2}$ (6400-5900 a.C.) podrían ser vestigios de otros muchos poblados que se extendieron por la llanura aluvial del Eufrates y que pastorearon animales de esta especie.

El objetivo inicial de las primeras capturas de reses vivas fue, sin duda, la formación de grandes rebaños que contribuyesen al abastecimiento de reservas cárnicas. Aislados de su entorno salvaje y protegidos a la vez de enemigos potenciales, la muerte natural o el sacrificio de alguna de ellas debió llevar consigo su reposición con uno o varios ejemplares nuevos. Esta primitiva práctica continuó vigente incluso en época histórica, ocasionando diversas alteraciones y variabilidades genéticas dentro de una misma cabaña ganadera. El control efectivo de la crianza de estos animales coincidió con el momento de consolidación de la aldea agrícola ${ }^{3}$ como unidad económica dominante (ca. 4000 a.C.). La selección de lugares para este tipo de asentamientos siempre estuvo en relación con varios factores: la obtención de materias primas, la calidad de los terrenos para el cultivo y, sobre todo, el fácil acceso a los recursos hidrológicos fueron algunos de los más importantes. Como es sabido, el ganado vacuno demanda una mayor cantidad de agua y de hierba fresca ${ }^{4}$ que el ovino y caprino, a la vez que presenta mayores dificultades de desplazamiento para ir en busca de estos elementos. Esta condición, además de su utilidad en la tracción de artefactos agrícolas y vehículos rodados, limitó su presencia a la cercanía de las zonas más densamente habitadas, situadas por lo general en las bien regadas planicies aluviales. Se crearon, así, las bases potenciales de los futuros conflictos entre los intereses de agricultores y ganaderos, cuyo control terminaría en manos de un poder central.

Durante los dos milenios siguientes (V-IV milenio a.C.), la estructura organizativa de las aldeas agrícolas del Próximo Oriente fue evolucionando hacia la constitución de sociedades urbanas. De forma paralela, la observación de los hábitos y comportamiento de los animales indujo a un más amplio aprovechamiento de los recursos ${ }^{5}$ que ofrecían y, como consecuencia, a una serie de actividades especializadas ejercidas por diversos profesionales. De este

2 HoolJer, D.A.: 1966. Preliminary Notes on the Animal Remains found at Bouqras and Ramad in 1965. Les Annales archéologiques arabes syrrenes, 16 (2) ; CLASON, A.T.: 1980. The Animal Remains from Tell es Sinn compared with those of Bouqras. Anatolica, 7.

3 Herre, W./ Rohrs, M.: 1977. The Origins of Agriculture: Zoological Considerations on the Origins of Farming and Domestication. En, REED, $\mathrm{CH}$. (Ed.). Origins of Agriculture. La Haya.

4 DAHL, G./ HJORT, A.: 1976. Having Herds: Pastoral Herd Growth and Household Economy. Stockholm, pp. 239, 247.

5 Sherrat, A.: 1981. Plough and Pastoralism: Aspects of the Secondary Products Revolution. En, HODDER, I. Pattern of the Past. Cambridge. 
modo, el bovino no sólo continuó siendo un excelente proveedor de carne para el consumo, sino que se convirtió en un importante productor de leche, piel, cuerna y estiércol. A estos beneficios hay que añadir su utilización como bestia de tiro y de labor, a partir del IV milenio a.C.

La valiosa condición de esta especie dejó sentir muy pronto su influencia sobre los esquemas sociales y religiosos de las comunidades del Cercano Oriente, donde la riqueza ganadera ${ }^{6}$ estuvo siempre vinculada con determinados y preponderantes estamentos civiles y sacerdotales. En este contexto, la figura del pastor, como gran conocedor del mundo del ganado, se constituyó como elemento fundamental del desarrollo económico.

Marco adecuado para le exposición de estas y otras consideraciones es el extremo sur de la región mesopotámica, territorio donde floreció la antigua civiliżación sumerio-acadia (figura 1). Los primeros núcleos de población allí

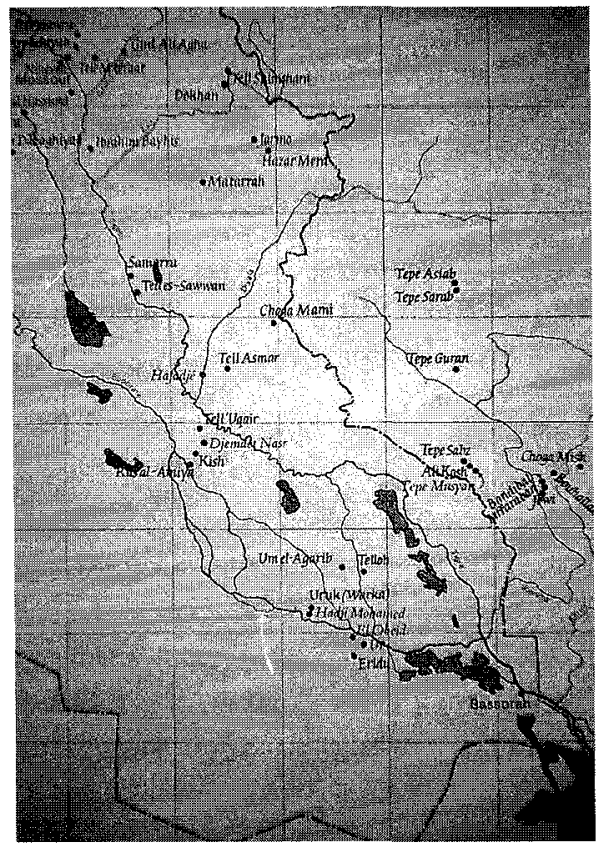

Figura 1. Mapa de Mesopotamia. Poblamiento neolítico y calcolítico.

6 Delgado, C.: 1996. El toro en el Mediterráneo. Madrid, pp. 119-127. 
observados se fechan en torno al 5000 a.C., si bien es cierto que pudieron existir grupos seminómadas con anterioridad. La denominada cultura de EI Obeid (ca. 5000-3750 a.C.) ${ }^{7}$ señala el comienzo de su colonización por gentes asentadas en aldeas dispersas, que practicaron la agricultura y la ganadería. Yacimientos arqueológicos como Ras al 'Amiya ${ }^{8}$ y Eridú ${ }^{9}$ testimonian la superioridad de la cabaña vacuna sobre la ovina y caprina.

Las primeras superficies empleadas como campos de cultivo y pastizales ocuparon las áreas más cercanas a los cursos de agua. Pero, el crecimiento demográfico fue alejando de los ríos las tierras disponibles, haciendo necesarias nuevas fórmulas de irrigación. La incipiente canalización de los caudales ${ }^{10}$ desembocaría mucho después de la aparición del Estado en obras hidráulicas a gran escala.

El bovino que pastaba en los prados mesopotámicos presentaba dos biotipos ${ }^{11}$, que corresponden a los modelos plásticos representados sobre vasos rituales y sellos cilíndricos de las etapas cronológicas de Uruk (3750-3200 a.C.) y Jemdet-Nasr (3200-2900 a.C.): existieron animales gruesos, de carnes colgantes, patas cortas y cuernos pequeños, junto a otros más finos y esbeltos que lucían una larga encornadura (figuras 2 y 3 ). Es probable que el ganado cuernilargo, muy abundante en el IV milenio a.C., fuera de origen autóctono, mientras el bovino cuernicorto, que empezó a reemplazar al anterior a partir del 3000 a.C., pudo proceder del vecino reino de Elam. Datos relativos a estos y otros animales domésticos han sido conocidos a partir de algunas tablillas administrativas ${ }^{12}$ del período arcaico (ca. 3000 a.C.), halladas en la ciudad de Uruk. En ellas se aplican los términos $g u_{4}$ y ab para designar al toro y a la vaca respectivamente, diferenciando también a los terneros según su

Redman, CH.: 1990. Los orígenes de la Civilización. Barcelona, pp. 317-325, 335-337.

StronaCH, D.: 1961. The Excavations al Ras al 'Amiya. Iraq, 23.

9 Flannery, K.V./ Whight, H.: 1966. Faunal Remains from "Hut Sounding" at Eridu, Iraq. Sumer, 22, pp. 61-63.

10 Adams, R.: 1958. Survey of Ancient Water Courses and Settlements in Central Iraq. Sumer, 14; Mitchell, W.: 1973. The Hydraulic Hypothesis: A reappraisal. Current Anthropology, 14(5), pp. 532-534; AdAMs, R.: 1974. Historic Pattern of Mesopotamian Irrigation Agriculture. En, DOWNING, T.E./ GiBson, Mc. (Ed.). Irrigations impact on Society, Anthropological Papers of the University of Arizon, 25. Tucson.

11 ISAAC, I.: 1962. On the Domestication of Cattle. Science, 137, n. ${ }^{\circ} 3.525$, p. 200; ZeUNER, F.: 1963. History of Domesticated Animals. London, p. 217; EPSTEIN, H.: 1971. Origin of the Domestic Animals of Africa. London, p. 250.

12 GREEN, M.W.: 1980. Animal Husbandry at Uruk in the Archaic Period. Journal of Near Eastern Studies, 39,1, p. 6. 


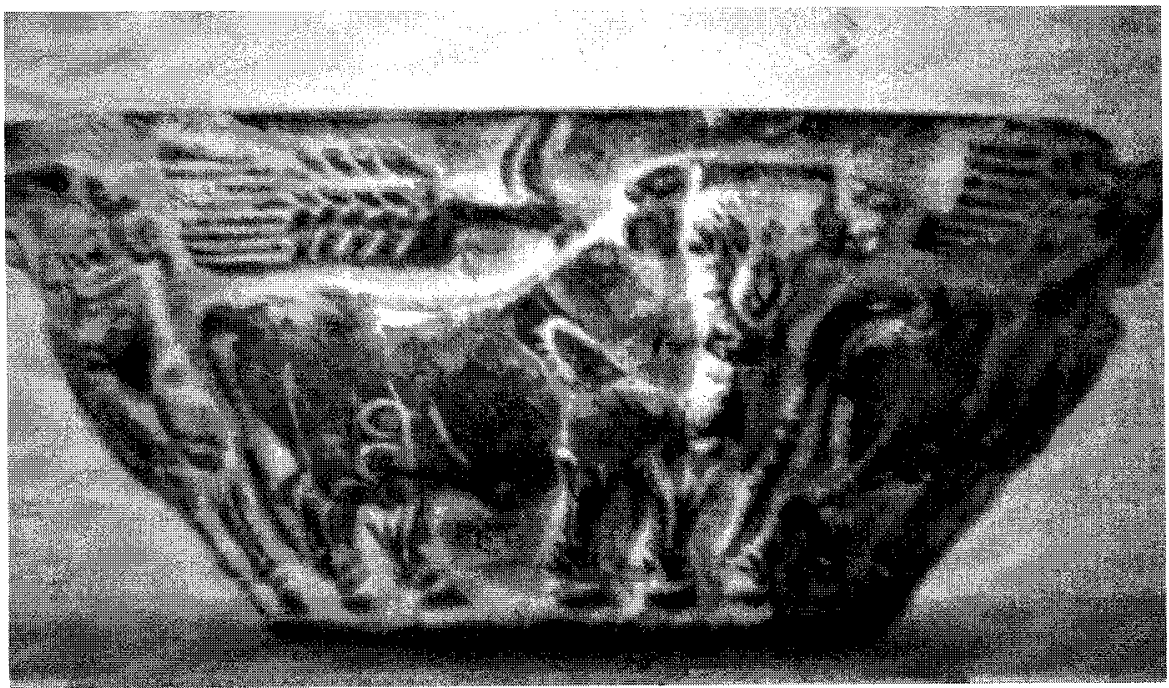

Figura 2. Cuenco ritual. Ur, ca. 3350 a.C. Esteatita. Museo de Iraq (Bagdad).

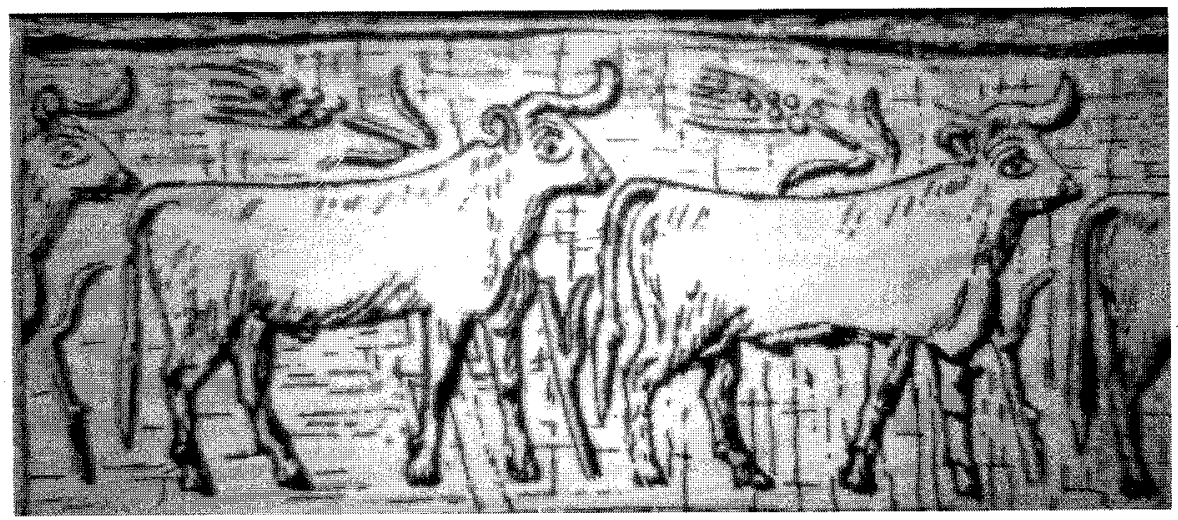

Figura 3. Impronta de sello cilíndrico. Mesopotamia, ca. 3350 a.C. Caliza. Museo El Louvre (París).

sexo (amar.kur, macho; amar.sal, hembra). Las capas de color más frecuentes eran la blanca y la negra ${ }^{13}$, además de la variedad conocida hoy como pía (fondo blanco con manchas de otro tono más o menos extensas).

13 LARA, F:: 1988. Himnos sumerios. Madrid, p. 24. 


\section{LA ESTABULACIÓN Y EL PASTOREO}

El bovino acostumbraba a estabularse en cabañas construidas con materiales poco estables como cañas, esteras, etc., muy similares a las empleadas hoy por los habitantes de los pantanos del sur de Iraq. Su representación iconográfica se repite una y otra vez como motivo decorativo de pedestales de piedra, sellos cilíndricos y trabajos de incrustación desde el período de Uruk hasta el dinástico arcaico (3750-2340 a.C.). A menudo, la cabaña se adorna con largos y prominentes postes anillados ${ }^{14}$ que le confieren un carácter sagrado. Aunque el significado de estos objetos es desconocido, en el arte posterior de los períodos neosumerio y babilónico aparecen siempre unidos a una deidad masculina (tal vez Adad o Shamash), cuya encarnación simbólica pudo tener su origen en estas primeras representaciones. Parece clara la tendencia a asociar este elemento con escenas de estabulación bovina, en tanto que el símbolo sagrado de la diosa Inanna, un haz de cañas en forma de cayado, suele aparecer con más frecuencia en relación con el ganado ovino. En la gran mayoría de estas escenas, dos terneros emergen de los laterales de la cabaña, mientras la puerta, situada en su parte frontal, permanece despejada. En derredor deambula el resto del rebaño, a menudo formado por hembras de ubres bien visibles (figura 4). P. Delougaz ${ }^{15}$ interpreta este tema como un episodio

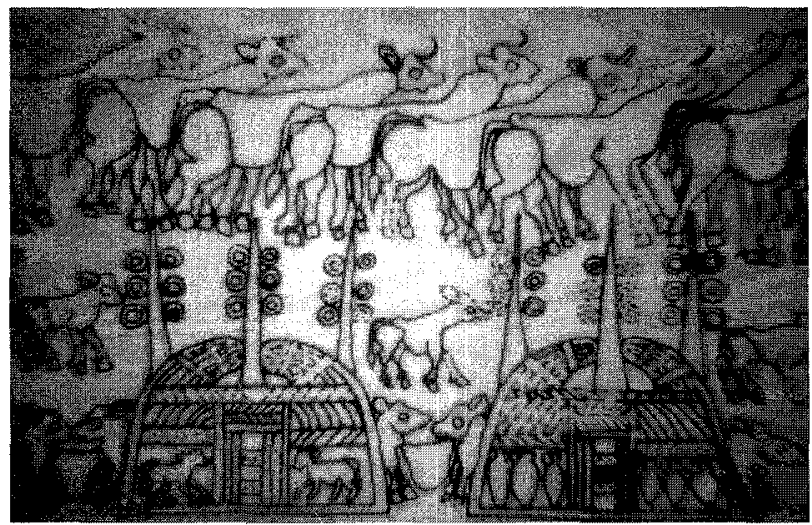

Figura 4. Impronta de seilo cilíndrico. Uruk, ca. 4000-3100 a.C. Magnesita. Museo Ashmolean (Oxford). 
de nacimiento de animales, en el que el vientre de la madre sería sustituido por la choza-establo. Notablemente, entre los pictogramas grabados sobre las tablillas de Uruk IV ${ }^{16}$ existen cabañas del mismo tipo que las aquí descritas. Uno de ellos simboliza el nombre de una diosa y además va unido a la idea de nacimiento.

Durante todo el período dinástico (2900-2340 a.C.), las representaciones de estabulación de animales desvían su interés hacia el desarrollo de la actividad humana. La figura del pastor como principal responsable del bienestar del ganado, aparece a menudo tanto en las composiciones literarias como en las representaciones artísticas. Las citadas tablillas de Uruk ${ }^{17}$ designan como pa-nám-rad al individuo que se ocupa indistintamente de los animales domésticos, cualquiera que sea su especie (ovino, caprino y vacuno). A comienzos del período dinástico temprano, se observa ya la tendencia hacia una especialización pastoril por cabañas ganaderas. Las representaciones muestran al pastor desnudo o ataviado con una simple falda corta, a veces adornada con flecos. Empuña un cayado con el que maneja a sus animales o los fustiga con una vara flexible. Una flauta ameniza sus largas horas de soledad ${ }^{18}$. A veces figura junto al ganado un varón vestido con largo faldón de tejido reticulado, barbado y cubierto con un tocado circular, similar al lucido por jefes o notables hasta época acadia. Podría personificar a monarcas o sacerdotes atendiendo a rebaños propios o del templo.

Entre las tareas pastoriles más comunes estaba la de llevar a los animales a los mejores pastos de las marismas o de la estepa ${ }^{19} \mathrm{y}$ la de suministrarles cantidades suplementarias de forraje, bien por carestía de hierba, bien para su engorde ${ }^{20}$. La palabra sumeria al.da (acadio, aldum) indica el conjunto de grano empleado como simiente en el campo y el molido en forma de harina empleado como pienso. El ganado era también aficionado a la ingesta de espigas de trigo o cebada y de un tipo de caña dulce, conocida como $z i^{21}$. Los pastores solían dormir en el suelo ${ }^{22}$, cerca de sus rebaños, y consumir pan y cerveza ${ }^{23}$. De esa interrelación entre pastores y animales, surgió el profundo

16 Falkenstein, A.: 1936. Archaische Texte aus Uruk. Berlín, sign. 213.

GREEN, M.W.: 1980. Opus, cit., p. 12.

LARA, F.: 1988. Opus, cit., p. 82.

LARA, F.: 1988. Opus, cit., p. 24.

20 LIMET, H.: 1991. Les animaux d'elevage en Mesopotamie ancienne. Colloques d'histoire des connaissances zoologiques, 2. Université de Liège, Mars, 1990, p. 33.

21 LARA, F.: 1988. Opus, cit., p. 157.

22 Lara, F.: 1992. Poema de Gilgamesh. Madrid, p. 28.

23 LARA, F.: 1992. Opus, cit., p. 30. 
conocimiento que los primeros tuvieron sobre la vida de los segundos y que ha quedado reflejado en los textos inscritos de aquellos pueblos. Se sabe que valoraban como ejemplares jóvenes a los menores de 4 años, después ya no se les tenía en cuenta para la producción. Las vacas eran fecundadas con sementales que en los documentos de Ur ${ }^{24}$ reciben el nombre de toro reproductor, $g u_{4}$.áb.ba. Además, el léxico sumerio establecía nominaciones distintas para las hembras fecundadas, las preñadas y las no preñadas, las que parian y las que abortaban; también se diferenciaba entre los terneros nacidos con retraso, los débiles y los prematuros. Sin duda, se practicó la técnica de la castración, pues los textos indican cuándo el toro está entero $\left(g u_{4}, g i\right.$ ǐ.dù). Los acadios ${ }^{25}$ empleaban el término tap.tíru para referirse al toro castrado.

La protección de sus ganados del ataque de ciertos depredadores fue motivo de constante preocupación para pastores y criadores. La iconografía relivaria de mitad del IV milenio representa de modo habitual a un hombre musculoso y barbado, que lleva por todo atuendo un cinturón de cuerda y un calzado puntiagudo. Su misión es la defensa del vacuno de la mortal agresión de los leones (figura 5). Desde el período dinástico

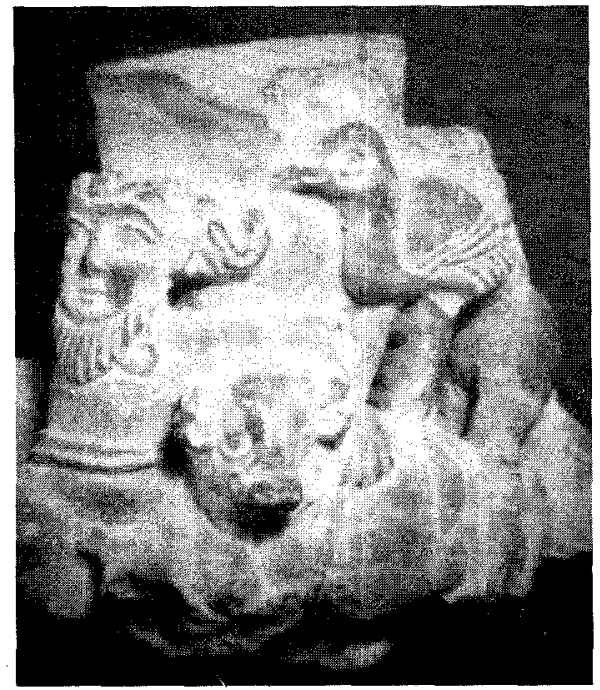

Figura 5. Vaso ritual, Uruk, ca. 3350 a.C. Piedra calcarea. Museo Británico (Londres). 
temprano II hasta el final de la era acadia (2700-2159 a.C.), la glíptica mesopotámica añade a este personaje la figura del hombre-toro. Como aquél, esta extraña y temible criatura, mezcla de humano y de bovino, libera a reses incautas de las garras de esos fieros animales (figura 6). Ambos simbolizan la exaltación heroica y artística de la imagen del pastor. Realeza y divinidad no fueron ajenas a este protagonismo, asumiendo a través del lenguaje figurativo titulaciones pastoriles relativas a su ministerio. Baste citar como ejemplo a Gudea, rey de Lagash (2144-2124 a.C.), que recibía el apelativo de pastor fiel ${ }^{26}$ o a Enlil ${ }^{27}$, señor de Nippur, que era conocido como pastor de los Cabezas Negras ${ }^{28}$. Ciertas plegarias e himnos religiosos acudieron también a símiles pastoriles para invocar la protección divina sobre Sumer o sobre sus gobernantes. Así se ruega a la diosa Nininsinna ${ }^{29}$ : "El país de Sumer (repose a través de $t i$ en pasto exhuberante) ${ }^{30}$ y en los himnos sumerios dedicados a Urnammu, rey de Ur (2111-2094 a.C.), éste justifica su elección como monarca diciendo: «El pasto y el abrevadero (...) fueron buenos para mi después de que tomé su gobierno» ${ }^{31}$, «El (Enlil) ha colocado la peculiar corona de la realeza en mi cabeza, ha obligado al santo cetro que dirija a

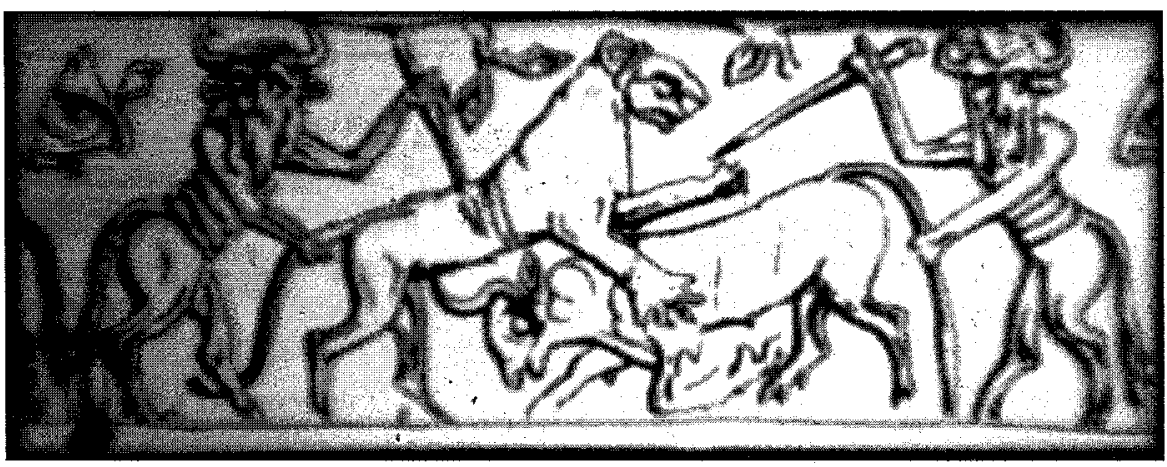

Figura 6. Impronta de sello cilindrico. Tell Agrab, ca. 2800 a.C. Instituto Oriantal de Chicago.

LARA, F.: 1988. Opus, cit., p. 116.

${ }^{27}$ ENLIL: Dios de la ciudad de Nippur, señor del viento y jefe del panteón divino.

${ }^{28}$ LARA, F.: 1988. Opus, cit., p. 24. Cabezas Negras era una forma de denominar a los sumerios.

29 Nininsinna: Señora de la ciudad de Isin. Nombre de Inanna, divinidad del amor y de la guerra.

30 LARA, F.: 1988. Opus, cit., p. 127.

31 LARA, F.: 1988. Opus, cit., p. 154. 
toda la gente de mi tierra, el báculo y el cayado para la dirección de las numerosas gentes...» ${ }^{32}$.

\section{LOS PRODUCTOS LÁCTEOS Y SUS DERIVADOS}

Entre las actividades pastoriles más características estuvo siempre el ordeñe de los animales. El vaquero realizaba esta labor acomodado detrás de la hembra y manteniéndole siempre la cola levantada mientras actuaba. Esta posición, de uso corriente hasta hoy para extraer la leche de ovejas y cabras, indica el origen ovino y caprino de este procedimiento y su adaptación posterior al vacuno tras su domesticación. Para estimular las glándulas mamarias del animal y facilitar la expulsión del líquido, solía insuflársele aire por la vagina o por el recto de modo oral (figura 7). Para impedir el acercamiento de terneros lactantes a las ubres maternas, se les colocaba un bozal de cuerda en torno a la boca. Su presencia allí provocaba en la madre la subida de la leche. Ésta era recogida y guardada en grandes vasijas provistas de asa en espera de su aplicación para la obtención de mantequillas y aceites, quesos y yogures. El queso era elaborado a base de sal y de un condimento mal conocido llamado gazi ${ }^{33}$. Las razas lecheras solían pertenecer al biotipo de vacuno cuernicorto.

Durante el período presargónida (2675-2355 a.C.), hubo lugares como Lagash, donde los pastores trabajaron como servidores del Estado, entregando al menos gran parte de los productos ganaderos a administradores designados para ello. En época neosumeria (2100-2000 a.C.), los pastores actuaron como contratistas, asumiendo toda la responsabilidad sobre el incremento o la pérdida de reses arrendadas al Estado y pagan-

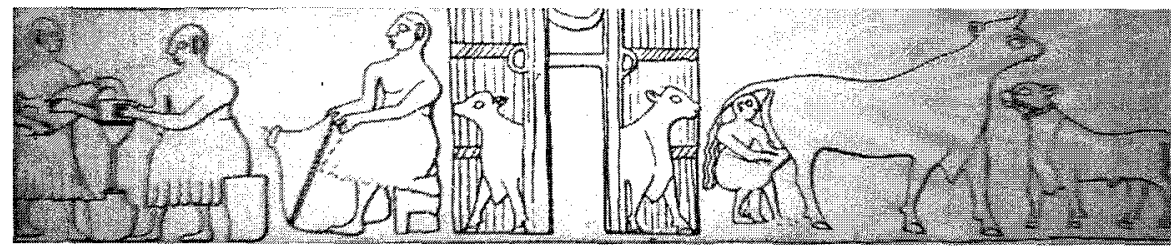

Figura 7. Relieve mural. Templo de Ninhursag, El Obeid (Ur), ca. 2900 a.C. Museo de Iraq (Bagdad).

32 LARA, F.: 1988. Opus, cit., p. 156.

3a Engluno, R.K.: 1995. Regulating Dairy Productivity in the Ur III Period. Orientalla, Nova series, 64(4) p. 417 ss. 
do un canon fijo sobre la producción. Un texto ${ }^{34}$ procedente de la antigua Puzris-Dagan (Drehem), importante centro administrativo al sur de Nippur, instituido por el rey Shulgi (2093-2046 a.C.) en el año 39 de su reinado, contiene contribuciones teóricas sobre artículos lácteos cuyo fin era servir de referencia y guía a los pastores. El cómputo ideal se establecía en un ternero anual por cada dos vacas, y 5 sila (5 litros) de aceite de manteca y 7,5 sila (7,5 litros) de queso por cada hembra disponible. Si no se alcanzaban las cantidades propuestas, la diferencia podía suplirse por otros derivados como leche cruda o agria. Esta fórmula podría también extenderse a las ciudades de Ur y Umma durante el mismo período. Los textos ${ }^{35}$ de la época documentan, además, la existencia de una serie de empleados implicados en la cría de vacuno entre los que se incluían ganaderos, jefes de establo, mayorales e incluso un ministro para actividades pecuarias. Todos ellos actuaban bajo la autoridad estatal.

Los supervisores del ganado llevaban una estricta contabilidad ${ }^{36}$ sobre los beneficios obtenidos por arrendadores y arrendatarios de animales. Estas cuentas eran nominales y estaban divididas en tres secciones: débitos, créditos y balance entre los anteriores. El débito consistía en la cantidad de ganado arrendada por el Estado a un particular o pastor en concepto de inversión. El crédito era el producto que éste entregaba al Estado como fruto de su trabajo y como compensación económica por el arriendo efectuado. Si al final del ejercicio, el balance de la cuenta presentaba déficit o superávit, éste se incorporaba al débito o al crédito del año siguiente. Los contables estatales extendían los correspondientes recibos, probablemente por duplicado, por cada entrega realizada por el pastor. Los templos fueron también parte interesada en estos contratos, pues poseían gran número de cabezas de ganado que precisaban de un competente personal. El templo de Ninhursag ${ }^{37}$, en El Obeid, estaba concebido como una vasta granja de vacuno con recintos destinados a la fabricación de lácteos. El Museo Británico conserva uno de los famosos frisos que decoraba este lugar. Representa las tareas de ordeñe y el proceso de preparación de la leche para transformarse en productos derivados. Para ello, primero se batía a mano dentro de grandes cántaros y

34 Genouillac, H. De: 1911. Textes cuneiformes du Louvre, 2. 5499.

35 KiENTZ, J.M.; LAMBERT, M.: 1963. L'elevage due gros betail a Lagash au temps du Lugalanda et d'Urukagina. Revista degli Studi Orientalia, 38.

36 Englund, R.K.: 1995. Opus, cit., pp. 403-424.

37 Ninhursag: Señora de la montaña, diosa materna esposa de An. Madre de los dioses. 
después se vertía en otro recipiente a través de un embudo o colador. Aquí permanecía herméticamente cerrada para su fermentación (figura 7). También el templo de Eninnu, en Girsu, consagrado a Ningirsu, divinidad principal de Lagash, disponía de una vaquería propia, el Egu o Casa de vacas ${ }^{38}$, y de un recinto para la elaboración lechera, el Eigara o Casa de la grasa y de la leche cremosa ${ }^{39}$. El santuario del dios lunar Nanna, en Ur, era conocido por sus vacas de negro pelaje, que pastaban con sus becerros por los verdes prados sagrados. De su leche se obtenía una excelente cuajada ${ }^{40}$.

El uso de la leche de vaca se extendió además al ámbito ritual. Los textos de Uruk ${ }^{41}$ testimonian que este elemento formó parte de las libaciones divinas y de las ofrendas diarias consagradas a dioses como Anu ${ }^{42}$. Por otro lado, el deseo de algunos monarcas de vincular la realeza con la divinidad, les indujo a declaraciones de filiación con ciertos dioses. El carácter esencialmente materno de las deidades femeninas elegidas, expresaba ese parentesco bajo la imagen de una vaca amamantando a su ternero. Reyes como Mesilim de Kish (ca. 2550 a.C.), Eannatum de Lagash (ca. 2470 a.C.) o Lugalzagesi de Uruk (ca. 2340-2316 a.C.) adoptaron la fórmula alimentado con la leche de Ninhursag ${ }^{43}$ en prueba de su devoción y dependencia.

Esta deidad aparece en las invocaciones religiosas bajo la forma de una Vaca lunar, esposa de Nanna, la luna, cuyo rayo era poéticamente evocado como el chorro de la Vaca fecunda ${ }^{44}$.

\section{LA INDUSTRIA PELETERA}

La piel de vacuno fue altamente valorada en el mundo mesopotámico. Una vez separado el pellejo de la carne del animal, la parte cen-

\footnotetext{
38 LARA, F.: 1996. Himno al templo Eninnu. Madrid, p. 85.

39 LARA, F:: 1996. Opus, cit., p. 99.

40 LARA, F.: 1988. Opus, cit., pp. 192-193.

41 Sachs, A.: 1955. Akkadian Rituals. En, Pritchard, J.B.: Ancient Near Eastern Texts. Princeton, pp. 338-343.

42 AnU: Primitiva divinidad sumeria. Personificaba la majestad de la realeza, el orden y la autoridad.

43 LABAT, R.: 1939. Le caractere religieux de la royauté assyro-babilonienne. París, pp. 63-69; Sollbeger, E. Kupper, J.R. 1971. Inscriptions royales de Sumer et Akkad. París, pp. 47, 93.

44 Hentze, C.: 1932. Mithese et symboles lunaires. Ambers, pp. 79-80.
} 
tral, el corium o dermis, era preparado por sucesivos procesos ${ }^{45}$ a base de soluciones de sal, harinas fermentadas, zumo de uva, vino, cerveza y leche para evitar su putrefacción. Después, el material se golpeaba una y otra vez para afinar su textura y se colocaba bien estirado sobre estacas o armazones de madera hasta que se abrían grietas sobre su superficie. Al principio, el curtido de la futura piel se realizaba enterrándola en hoyos excavados en el suelo, más tarde se prefirieron grandes vasijas. Ingredientes como el alumbre, la hiel de roble ${ }^{46}$, la corteza de granado, las hojas de ciprés, el zumaque o las vainas de acacia contribuían a ello. Los colores de las pieles se obtenían a partir de productos vegetales (gama variable desde el tono crema al castaño rojizo) y del alumbre (tonalidades blancas), pero su intensidad variaba según las capas de los agentes aplicados. El color se fijaba con tintes o sumergiendo el cuero en soluciones de vinagre, hierro, azafrán, etc.

En torno a la piel surgió toda una floreciente industria de manufacturas entre cuyos artículos destacaba el calzado ${ }^{47}$. Los sumerios empleaban sandalias y chapines. Las primeras, más rudas, servían para andar fuera de la casa; los segundos, más lujosos, para el interior de la vivienda. Los curtidos peleteros se emplearon para el recubrimiento de puertas, sillas, tronos, arneses y monturas, así como para la fabricación de odres y contenedores de líquidos y sólidos. Algunos de estos objetos aumentaron su valor, decorándose con dibujos hechos con polvo de oro. En el ámbito castrense, la piel se usó para recubrir los cascos, armaduras y escudos con que se pertrechaban los soldados, además de carcájs de cuero llenos de flechas. En la esfera de lo sagrado, este material formó parte de algunos rituales religiosos. Así, servía de vestido ceremonial a ciertos sacerdotes del santuario de la diosa Nanshe ${ }^{48}$, en Sirara, y se revestía con ella el timbal cultual de los templos ${ }^{49}$.

45 ForBes, R.J.: 1966. Studies in Ancient Technology, IV. Leiden, pp. 40-46; Reed, R.: 1972. Ancient Parchments and Leathers. London, p. 88 (table 2).

46 HIEL DE ROBLE: Abultamiento rico en tanino que se produce en la corteza del árbol a causa del huevo de un insecto.

47 Genoulllac, H. De: 1938. La chausure sumerienne. Revue d' Assyriologie, 7, pp. 157159.

48 NANSHE: Diosa de la ciudad sagrada de Sirara, cercana a Lagash. Hija de Enki y de Ninhursag.

49 SACHS, A.: 1955. Opus, cit., pp. 334-336. 


\section{LA TRACCIÓN AGRÍCOLA Y RODADA}

Los pictogramas de Uruk ${ }^{50}$ constituyen las primeras reproducciones, conocidas hasta hoy, de vehículos de arrastre (ca. 3200 a.C.). Representan trineos con y sin ruedas, que debieron de estar tirados por bovinos. En su versión para el transporte de personal, tenían un asiento adaptado bajo una cubierta que dejaba libre un espacio delantero donde permanecía en pie el conductor (figura 8). Los carros más primitivos se movían sobre ruedas macizas sujetas a un eje que sobresalia en forma de cubo. Sobre ellas se fijaba un sólido bastidor con asientos o barandillas laterales (figura 9). Con el tiempo, dicho cubo fue empotrado en una pieza central, encajada a su vez en otras dos con forma semilunar. La totalidad de la rueda iba asegurada con grapas o traviesas metálicas o de madera, y una llanta de rodadura. De este tipo fueron las ruedas de las carretas funerarias encontradas en los enterramientos reales de Kish, Susa y Ur ${ }^{51}$.

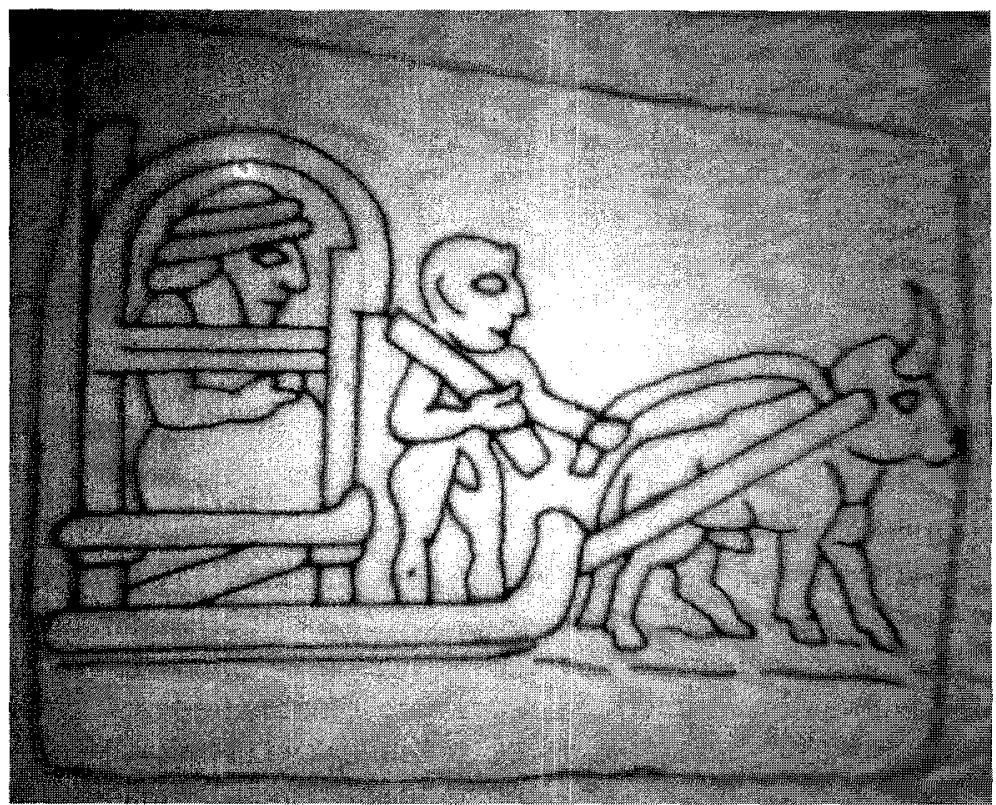

Figura 8. Signo pictográfico. Uruk, ca. 3000 a.C.

5o Falkestein, A.: 1936. Opus, cit. Signs. 742-745.

51 WOOLLEY, L.: 1934. Ur Excavations, 2. The Royal Cemetery. London. 


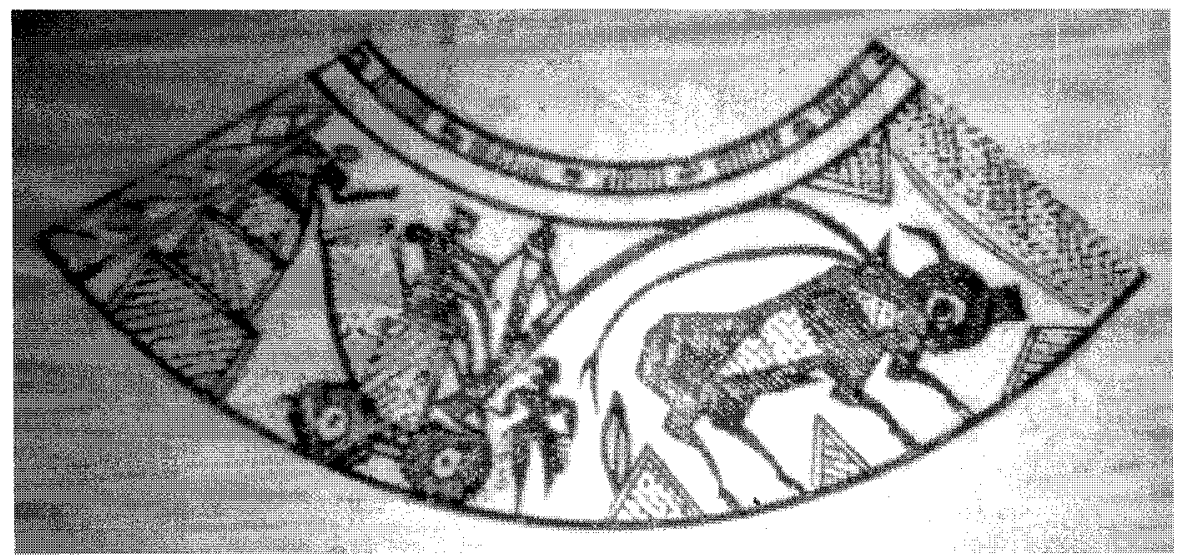

Figura 9. Fragmento cerámico. Susa, III milenio a.C. Museo de Teherán.

Todos estos progresos supusieron un avance notable en la evolución de los vehículos rodados. En Mesopotamia estuvieron en pleno uso hacia el 2000 a.C. La fuerza y capacidad para el tiro mostrada por el vacuno convirtió a estos animales en bestias preferentes para esta función. La prioridad otorgada a los machos sobre las hembras derivaba de la menor fortaleza y mayor lentitud de estas últimas. Los sumerios distinguían en su vocabulario entre buey de carro y buey de litera, gu .gis.mar.słlim y $g_{4}$. gis. mar.gid.da $^{52}$.

Los bueyes sustituyeron al hombre como fuerza motriz para el manejo de arados hacia el 3000 a.C. De este modo se pudo cultivar una mayor extensión de tierra en menos cantidad de tiempo. Nada ha quedado de los más antiguos modelos de madera, pero parece que estaban formados por dos palos en forma de horquilla para hacer el surco, y otro central más largo al que se ataban los cuernos de las bestias de tracción. La evolución de estos artefactos a otros más complejos dio como resultado lá expansión por Mesopotamia del arado de cama curva ${ }^{53}$. La glíptica acadia representa ejemplares de este tipo, algunos de los cuales incorporan una especie de embudo vertical donde se depositaban las semillas. Una vez en movimiento, éstas caían directamente en tierra, plantándose a una mayor

52 LIMET, H.: 1991. Opus, cit., p. 36.

53 Arado de cama curva: Arado cuya pieza central o cama, donde se engancha el timón, adopta forma curva. Su uso se extendió desde Mesopotamia hasta el Mediterráneo occidental. 
profundidad que con la distribución manual. Así se realizaba a la vez el surco y la siembra. En esta misma época se conocía también el arado de doble esteva y cama curva, y el radial. Los bueyes araban por parejas 0 en solitario, guiados por la vara del conductor de bueyes, sa.gu ${ }_{4}{ }^{54}$. Antes de volver a utilizar su sembradora, el campesino repasaba el campo con un rastrillo tirado por otro bóvido ${ }^{55}$. Después de recoger las mieses, los animales las pisoteaban bajo sus patas para separar el grano. Este trabajo se encomendaba en primer lugar a bueyes o vacas, pero eran las ovejas quienes terminaban la faena, recibiendo entonces el nombre de oveja que sigue al buey, udu.gu $u_{4}$ e.ús.sa ${ }^{56}$. Otras veces, las reses laboraban con trillos.

Con la invención del yugo, se abandonó la antigua costumbrẹ de uncir los bueyes con cuerdas o correas. Este artefacto fue creado expresamente para sujetarse al cuello de estos animales, adaptándose después a las caballerías (ca. 2000 a.C.) Se aplicó mucho antes a la tracción de arados que a la de carros en toda el área mesopotámica, siendo la modalidad yugal ${ }^{57}$ la más frecuente. El yugo estuvo asociado preferentemente al vacuno cuernilargo, mientras para el cuernicorto se emplearon collares, siguiendo la costumbre de sus introductores en Mesopotamia, los pueblos elamitas.

\section{CONCLUSIÓN}

La carne de vacuno formó parte raras veces de la dieta cotidiana de los pueblos mesopotámicos. La base de su alimentación fueron los cereales transformados en pan, galletas, pastas, etc. Aunque los textos hacen referencia a un bovino de pasto y a otro de cebado ${ }^{58}$, en clara alusión a su destino culinario, lo cierto es que este último estuvo reservado para la mesa de los poderosos y de la divinidad. Documentos administrativos sumerios y neosumerios ${ }^{59}$ registran el número de reses que entraban a diario en la cocina de notables y reyes. En alguno de ellos llega a contabilizarse

54 LAFONT, B.: 1985. Documents administratifs sumériens. París, p. 83.

55 LAFONT, B.: 1985. Opus, cit., p. 83.

56 LIMET, H.: 1991. Opus, cit., p. 36.

57 YUGO YUGAL: Se coloca sobre el cuello del animal, en vez de unirlo a los cuernos (yugo cornal).

58 LIMET, H.: 1991. Opus, cit., p. 23.

59 SigRist, H.: 1984. Sumerian Account Texts in the Horn Archaeological Museum. Michigan, n. ${ }^{\circ}$; LEWIS, B. JEWELL, E.R.: 1982. Sumerian Economic Texts. Acta Sumerologica, 4, n. ${ }^{\circ} 10$. 
hasta un total mensual de 51 bueyes y 24 vacas. Textos ${ }^{60}$ de tipo religioso atestiguan el beneplácito de los dioses cuando recibían viandas de vacuno procedentes de los sacrificios. El Girpana del Eninnu pudo ser una estancia dedicada a la inmolación de las víctimas que el templo necesitaba y que luego eran cocinadas en el recinto del Ekishuku ${ }^{61}$. La frecuente participación de los fieles en los ágapes sagrados suponía para muchos de ellos una ocasión, a veces única, de probar un manjar tan nutritivo como costoso. Los sumerios tomaban la carne cocida, hervida o asada y siempre bien condimentada.

Las listas lexicográficas sumerias mencionan a los encargados de dar muerte a las reses junto a los cocineros. El término con que se les designa $g u_{4} . g a z$, podría traducirse como matarife de bueyes ${ }^{62}$. Dado que la palabra sumeria gaz sería equivalente en acadio a palàqu o mahàsu, herir de un golpe, la muerte del animal podría producirse por la descarga de un hacha. En el relato de La muerte de Urnammu ${ }^{63}$, primer rey de la III dinastía de Ur, el propio monarca ejecuta a los bueyes de esa manera. Estas expresiones inducen a creer en la profesionalidad de tal actividad, sobre todo si se tiene en cuenta que el ovino moría degollado por el cuchillo de un matarife diferente, el degollador de ovejas. El poema sumerio sobre La maldición de Agadé ${ }^{64}$ aplica esta doble terminología al referirse al sacrificio de individuos pertenecientes a ambas especies.

Generalmente, los textos no especifican la edad de las víctimas, pero cuando lo hacen, éstas no sobrepasan los 3 años ${ }^{65}$. Ello podría significar que sólo mataban reses adultas o viejas con un menor rendimiento económico y que sólo consignaban por escrito la edad de aquellos animales que se salían de esta regla. Si esto fue así, es probable que el vacuno cebado fuera algo secundario y destinado a ocasiones especiales y confirmaría lo que se desprende de textos y documentos literarios y religiosos: que el consumo de carne de vacuno no desempeñó un papel esencial en la alimentación de estos pueblos, reservándose este tipo de ganado como

\footnotetext{
60 LARA, F.: 1988. Opus, cit., pp. 127, 165, 199.

61 LARA, F.: 1996. Opus, cit., pp. 85, 157 (núms. 7 y 9).

62 Materialem zum Sumerischen Lexicon, vol. 12. Rome, p. 36, 1. 98-99.

63 KrameR, S.N.: 1967. The Death of Ur-Nammu. Journal of Cuneiform Studies, 21, linea 80.

64 COOPER, J.: 1983. The Curse of Agade. Baltimore, lineas 237-238.

65 Sigrist, M.: 1983. Textes economiques neo-sumeriens de l'Université de Syracuse. París, n. 356 .
} 
fuente económica más rentable para la obtención de los llamados productos secundarios y para actividades agrícolas y de tracción.

La conclusión de este somero análisis es que el ganado vacuno influyó en gran medida no sólo en las formas de irrigación de las grandes praderas y de las mesetas dedicadas al pastoreo de reses, sino que se constituyó en un signo externo de una riqueza que iba a transferirse, incluso, a los planos más elevados de la realeza y de la divinidad. 